\title{
Development of MFM with Magnetic Fields Applied by Orthogonal Electromagnets and its Applications to Analysis of Magnetic Domain Structures
}

\author{
T. Yamaoka*,**, S. Hasumura*, K. Andou*, M. Tamura*, H. Tsujikawa*, A. Yamaguchi**, \\ and H. Miyajima** \\ * SII NanoTechnology Inc., 2-15-5 Shintomi, Chuo-ku, Tokyo 104-0041, Japan \\ ** Department of Physics, Keio University, 3-14-1 Hiyoshi, Yokohama, Kanagawa 223-8522, Japan
}

We developed a magnetic force microscope (MFM) where magnetic fields were applied by orthogonal electromagnets. This equipment can be used to observe magnetic domains by specifying an arbitrary angle while applying an external magnetic field of $5 \mathrm{kOe}$ or less. A dot and a rectangular thin film made of permalloy were measured with this equipment. The chirality of the vortex state in the permalloy dot could be determined by using this apparatus. Furthermore, the shape of the closure domain changed every time the direction of the magnetic field was changed by 45 degrees. These results are discussed in detail together with the micromagnetics simulations.

Key words: magnetic force microscopy, applied magnetic field, magnetic domain, micromagnetics simulations

\section{直交 2 軸電磁石型磁場印加 MFM の開発と磁区構造解析への応用}

\author{
山岡武博*,**蓮村聡* ・ 安藤和徳* ・田村政史*・辻川葉奈*・山口明啓** ・宮島英紀** \\ *エスアイアイ・ナノテクノロジー株式会社，東京都中央区新富 2-15-5 (言104-0041) \\ **慶応義塾大学理工学部, 神奈川県横浜市港北区日吉 3-14-1 (テ 223-8522)
}

\section{1. はじめに}

強磁性体の極微領域における磁気的性質を明らかにすることは, 基礎物理一の興味のみならず, 高密度化の進む情報ストレージの 分野をはじめ, 次世代の磁気デバイスなど応用面でも重要である. 強磁性体の極微領域を高分解能で調べる簡便かつ実用的な手法と しては, 磁気力顕微鏡 (MFM) 1)が挙げられる. MFM は走査型 プローブ顕微鏡 (SPM) の 1 種であり, 真空中 $\mathrm{Q}$ 值制御法と低モ 一メント探針を使った高分解能 MFM の分解能は $10 \mathrm{~nm}$ 台に達成 している. 2) カーボンナノチューブ (CNT) を使用した MFM 探 針では $10 \mathrm{~nm}$ 以下の分解能を持つ. 3) これらの技術開発により, 高密度磁気記録媒体の記録信号の観察や，パターンドメディアな ど次世代媒体を目指した微小磁気ドットの磁化状態に関する研究, ナノスケールの磁性体パターンの磁区構造観察などに MFM が多 く用いられてきた. 4 7)

極微領域の磁気的性質の探求には，このような静的な状態での 磁区観察以外に, 試料温度を制御しながら, あるいは外部磁場を 印加しながら磁気構造の变化を観察することが重要である. 安井 らは磁気記録媒体を加熱泠却しながら MFM 測定を行い，媒体の 微細構造と磁区構造の熱緩和について詳細に報告している. $\left.{ }^{8}\right) 山$ 岡らは, $\mathrm{N}$ 型フェリ磁生を持つ $\mathrm{Tb}-\mathrm{Fe}-\mathrm{Co}$ 膜の温度制御 MFM 測 定を行い，補償温度を境に磁化が反転する現象や熱プロセスによ る微細な磁区構造の変化を報告している．99)磁場印加 MFM につ いては，磁気記録媒体の磁気クラスターの消磁過程 10),や，磁性薄 膜・ドット・細線の磁区構造変化, 磁化反転過程 11, 12)などが報告 されている.

本研究では, MFM のシステムに, 1軸の電磁石系による水平 磁場印加を 2 組結合した直交 2 軸の電磁石系を付加し, それらの

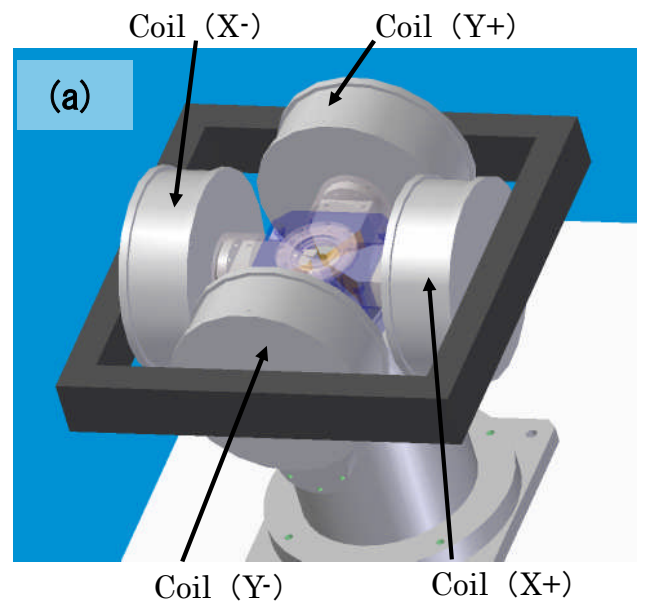

Pole piece

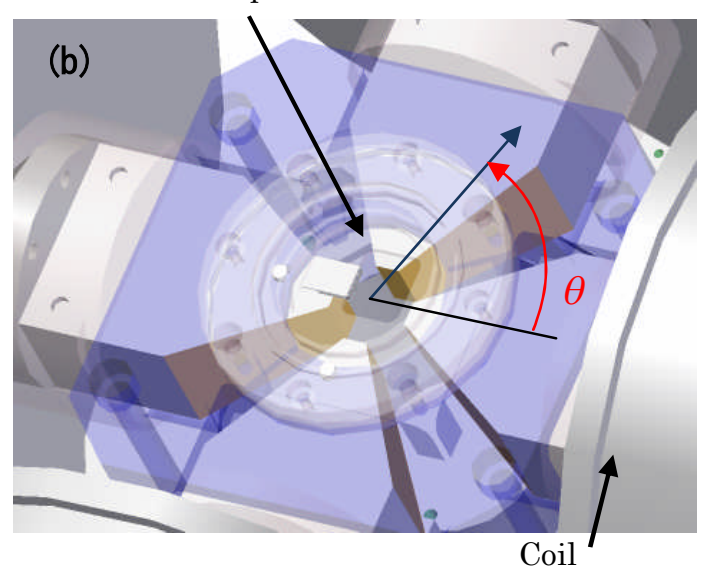

Fig. 1 (a) Schematic of orthogonal electromagnets. (b) Pole-piece arrangement in sample space. 
合成磁場によって，面内の任意の角度に最大 $5 \mathrm{kOe}$ までの外部磁 場を印加しながら MFM 測定が可能な装置を開発し, 磁区構造解 析への有効性を示すことを目的とした．開発した磁場印加 MFM を用いて，パーマロイ $\left(\mathrm{Ni}_{81} \mathrm{Fe}_{19}\right)$ 製の円盤の磁気渦や長方形薄 膜の還流磁区が外部磁場の向きによって変化していく過程を調べ これらの結果を National Institute of Standard and Technology (NIST) の提供する OOMMF ( Object Oriented Micro-Magnetic Framework) 13) を使ったよるマイクロマグ ネティックス計算結果と合わせて議論する.

\section{2. 装置}

Fig.1 に直交 2 軸電磁石型磁場印加MFM装置の概略図を示寸. Fig.1(a)のように，1軸上に2 個の電磁石を対置し，これを2組組 み合わせて直交させる。これら 2 軸の交点が試料位置となる.

Fig.1(b)は試料近傍の磁極配置を示す. 磁場の角度 $\theta$ は右側のコイ ルの中心軸を基準として表すことにする.

Fig.2(a)は $\theta=0^{\circ}$ の断面の概略図である. 磁極間の距離は $22 \mathrm{~mm}$, $\mathrm{Fe}$ 製の磁極の大きさは水平方向に $6 \mathrm{~mm}$, 垂直方向に $15 \mathrm{~mm}$ と し，できるだけ一様な磁場を印加するため，磁極の高さ中心と試 料面高さが同一になるように調整した. 磁極間は $\mathrm{Fe}$ 製のヨークで 磁気回路を形成した. 各コイルは 500 ターンの巻き数を持ち, 約 $7 \mathrm{~A}$ の電流を流した場合, 磁極間距離 $22 \mathrm{~mm}$ の空間に $5 \mathrm{kOe} の$ 磁

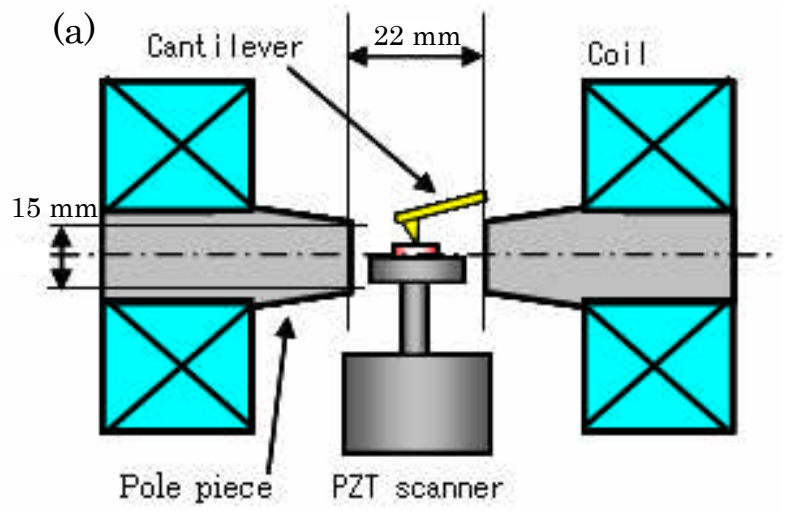

(b) Pole-piece (Y)

Pole-piece (X)

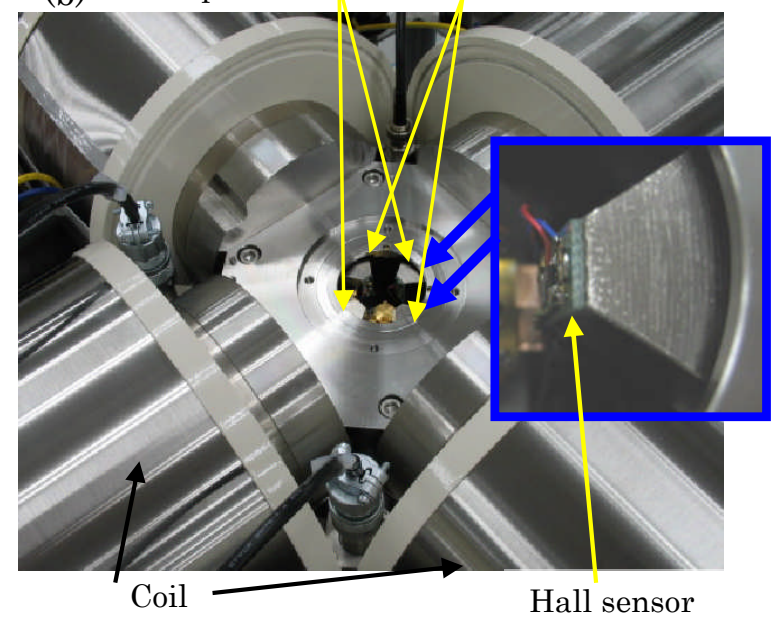

Fig. 2 (a) Cross-sectional schematic at $\theta=0$ degrees. (b) Photograph of pole pieces, coils and inset shows Hall sensors.
場が生じる．2軸の電磁石の組に流寸電流の配分比を変えること で印加する磁場の角度を制御した. Fig.2(b)に試料近傍の磁極付近 の詳細を示す． 2 軸の片側の磁極面にホール素子を取り付け，設 定磁場に対するフィードバック制御および磁場の校正に使用した.

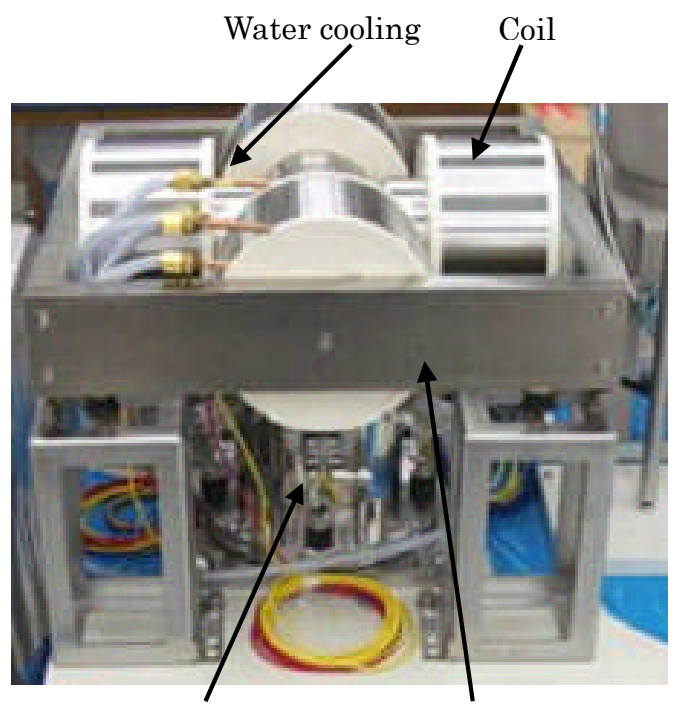

Vacuum chamber Magnetic circuit

Fig. 3 Photograph of MFM equipment with magnetic fields applied by orthogonal electromagnets.
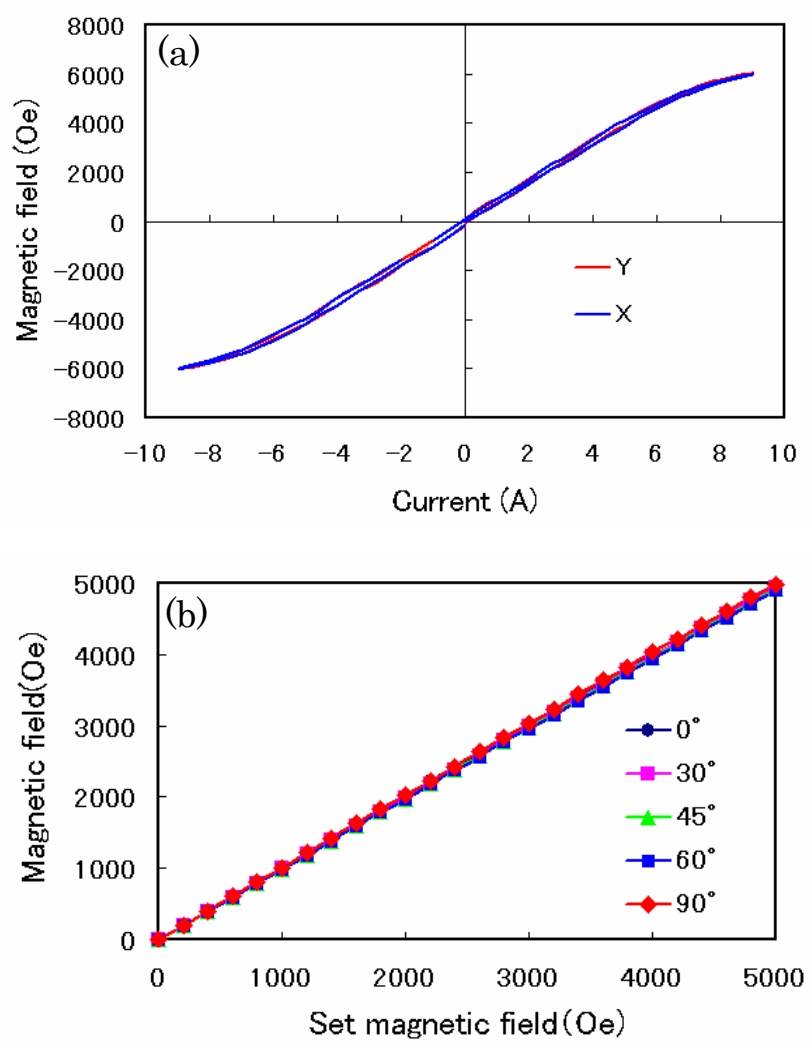

Fig. 4(a) I-H curves of orthogonal electromagnets. X and $\mathrm{Y}$ correspond to the two orthogonal axes. (b) Relation between set magnetic field and generated magnetic field after magnetic field was corrected. 
試料位置に別のホール素子を置き， $\theta=0^{\circ}$ 方向 (X 軸) と, $\theta=90^{\circ}$ 方向 ( $\mathrm{Y}$ 軸) とで, ソフトウェアで設定する磁場の值と試料位置 および磁極の片側に取り付けたホール素子で計測した磁場の関係 を求め, 磁場の校正を行った. ホール素子による磁場フィードバ ック機構により安定した磁場を長時間印加することを可能とした

Fig.3 は実際の装置写真である. MFMのベースマシンは環境制 御S PMシステム NanoNavi/E-sweep（S I I ナノテクノロジー 社製）を使用した。電磁石稼動時は水冷を行った。

Fig.4(a)は, 磁場フィードバックを OFFにして実測した電流磁 場特性である. X, Y 両方向ともほとんど同じ特性が得られた.ま た Fig.4(b)は角度 $\theta=0^{\circ}$ と $\theta=90^{\circ}$ て磁場を校正後, $\theta$ を $0^{\circ}, 30^{\circ}$, $45^{\circ}, 60^{\circ}, 90^{\circ}$ 設定した際の, 実際の発生磁場を測定した結果で ある，角度を変えても，設定した磁場の值と実測した磁場の值は 高い精度で一致した.

\section{3. 実験結果および考察}

\subsection{NiFe 円盤}

強磁性体の円盤の半径が減少すると, 静磁エネルギーと交換エ ネルギーが競合し, 安定な磁化配置の 1 つとして磁気渦（ボルテ ックス) 構造をとる. ボルテックスの中心で磁束は垂直の向きに 湧き出すか, 吸い込むが, 中心以外の場所では磁化は面内で旋回 している. MFM は原理的に試料からの漏洩磁場の垂直成分のみ 関与するため, 面内で旋回する磁束とは相互作用が無く, MFM 像 から旋回の向き（カイラリティ）は判断できない.

Fig.5 に直径約 $6 \mu \mathrm{m}$ ，厚み $0.4 \mu \mathrm{m}$ のパーマロイ $\left(\mathrm{Ni}_{81} \mathrm{Fe}_{19}\right)$ 円 盤を真空中 $\mathrm{Q}$ 值制御 $\mathrm{MFM}$ により無磁場の状態て観察した結果を 示す. MFM 探針は $\mathrm{Si}$ 製カンチレバー（バネ定数 $42 \mathrm{~N} / \mathrm{m}$, 共振 周波数 $350 \mathrm{kHz}$ ) に CoPtCr $24 \mathrm{~nm}$ をスパッタ・コートしたもの を用いた. 7) 測定における探針高さは $100 \mathrm{~nm}, \mathrm{Q}$ 值は約 6000 に 制御した. Fig.5(a)は表面形状像，(b)は MFM 像である. あらかじ め MFM 探針の先端は $\mathrm{S}$ 極に磁化させており，MFM 像からは， 円盤中央に磁束の湧き出し ( $\mathrm{N}$ 極) を示寸明点が観察された. こ の MFM 像を見ても, 円周部分にコントラストの変化は無く, カ イラリティは判断できない.

Fig.6(a, c)に, 磁場印加の角度 $\theta$ を $0^{\circ}$ と $180^{\circ}$ に設定し, 30 Oe の磁場を印加しながら MFM 測定した結果を示寸. Fig.5(b)は外部 磁場をゼロに戻した時の MFM 像である. 磁生体に外部磁場を印 加すると, 外部磁場と同じ向きの磁区が拡大し, 逆に外部磁場と 反対の向きをもつ磁区は縮小寸る.このことから，Fig.5(a)の弓型 をしている磁壁から下の大きな面積を占める部分の磁化は外部磁 場と同じ右向き $\left(\theta=0^{\circ}\right)$ のはずである. Fig.6(c)についても同様 である. 従って, MFM 像のみからこの円盤の磁気カイラリティ は「左回り」と推定できる.

Fig.6(d〜f)は Fig.6(a〜c)に対応するマイクロマグネティックス 計算結果である. 磁気力イラリティが「左回り」の場合のみ, 今 回の MFM 測定と整合した結果が得られた. 計算結果は $\theta=0^{\circ}$ と $\theta$ $=180^{\circ}$ の場合とで, 当然ながら点対称の磁区構造になっているが, 実際の MFM 測定では, 特に $\theta=180^{\circ}$ (Fig.6(c)）において, 弓型 の磁壁が左側にはあまり延びていない.この場所は Fig.5(a)の

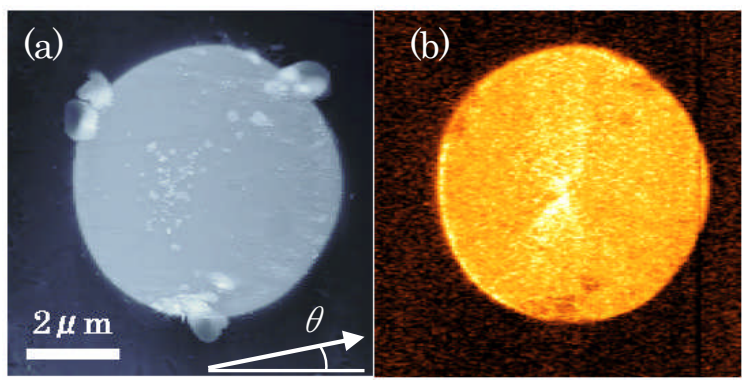

Fig. 5 (a) AFM image and (b) MFM image of $\mathrm{Ni}_{81} \mathrm{Fe}_{19}$ disk. $\theta$ indicates direction of magnetic field. (a) $\theta=0^{\circ}$

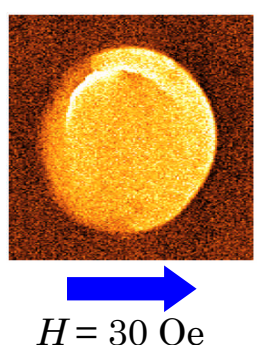

(b) $H=0(\mathrm{Oe})$

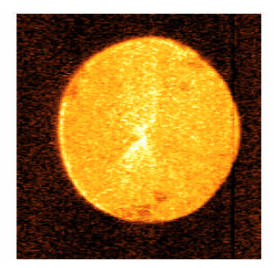

$H=30 \mathrm{Oe}$

(d)

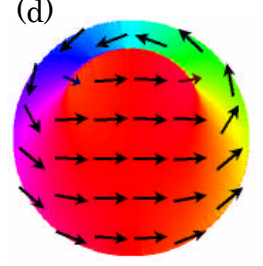

(e)

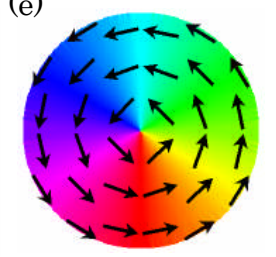

(c) $\theta=180^{\circ}$

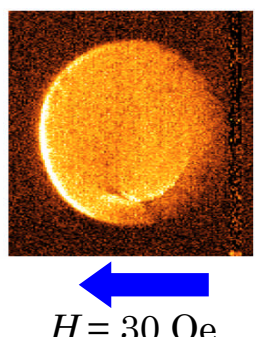

Fig. 6 MFM images (a) and (c) correspond to $\theta=0$ degrees and $\theta=180$ degrees. Arrows indicate directions of magnetic field. No magnetic field was applied for MFM image (b). Images (d)-(f) are micromagnetics simulations of MFM images (a)-(c).

AFM 像から, 異物または傷が確認でき, このような表面性状が影 響していると推定される.

\section{$3.2 \mathrm{NiFe}$ 長方形薄膜}

Fig.8(e)に磁場無しで, $9.2 \mu \mathrm{m} \times 6.3 \mu \mathrm{m} \times 0.4 \mu \mathrm{m}$ のパーマロイ長 方形薄膜の MFM 測定を行った結果を示す. 典型的な還流磁区が 観察された. 次に磁場の大きさ $20 \mathrm{Oe}$ を一定にし, 磁場角度 $\theta$ を 45 度ずつ変えていきながら MFM 測定を行った. その結果を Fig.8( $(a \sim d, f \sim i)$ に示寸. 便宜上, 印加した磁場の向きを太い矢印 で表している. 印加した磁場の向きと平行な磁区が拡大している 様子が明瞭に観察されている. わかりやすいように磁区の向きを 細い矢印で示した. この結果からも, 直交 2 軸電磁石型磁場印加 MFM の角度制御が正しく機能していることがわかる.

Fig.9(a〜d)はマイクロマグネティックス計算の結果である. 磁 場を印加した際の計算結果は $\theta=0^{\circ}, 45^{\circ}, 90^{\circ}$ の場合のみ示した. 形状の対称性から, ある磁場角度 $\theta$ で磁場印加した状態の磁区構 造と, $\theta \pm 180^{\circ}$ における磁区構造は等価であるため, $135^{\circ}, 180^{\circ}$ 等の計算結果は省略した. Fig.9 のマイクロマグネティックス計算 結果は Fig.8 の MFM 像と若干の差異も見られるが, 実験結果の 


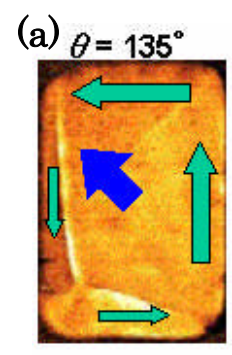

(d) $\theta=180^{\circ}$
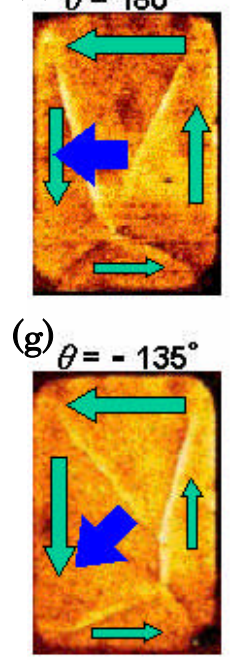

(b)

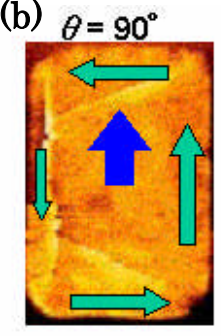

(e) $H=0(\mathrm{Oe})$

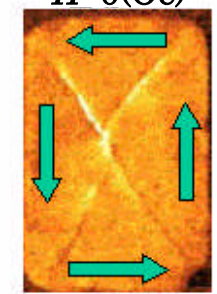

(h) $\theta=-90^{\circ}$

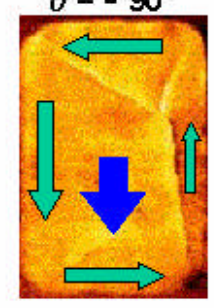

(c) $\theta=45^{\circ}$

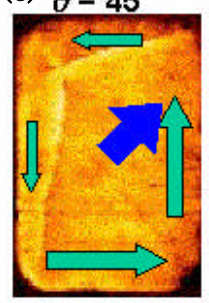

(f) $\theta=0^{\circ}$

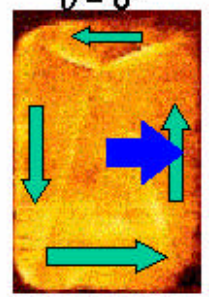

(i) $\theta=-45^{\circ}$

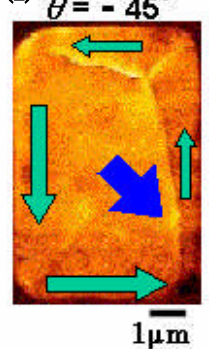

Fig. 8 Shape of closure domain changed every time direction of magnetic field was changed by 45 degrees. Wide arrows indicate directions of magnetic field. Narrow arrows indicate directions of magnetic domains.

\section{大部分を定性的に説明している.}

一方，Fig.8のMFM 測定結果においては，磁場角度 $\theta$ と， $\theta \pm$

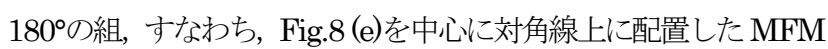
像同士において，磁区構造の対称性が一部失われている組がある. $\theta=0^{\circ}$ と $\theta=180^{\circ}$ のFM像の対称性は良いが， $\theta=90^{\circ}$ と $\theta=$ $-90^{\circ}$ の組，あるいは $\theta=45^{\circ} と \theta=-135^{\circ}$ の組の MFM 像の対称 性は良くない. $\theta=90^{\circ}$ では 180 度磁壁が現れているが, $\theta=-90^{\circ}$ では 180 度磁壁は無い. 同様に, $\theta=45^{\circ} に 180$ 度磁壁は見られず, $\theta=-135^{\circ}$ には 180 度磁壁がある. このような磁区構造の非対称 は，試料表面性状や結晶性の不均一，表面酸化などの化学的特性 の不均一，加工精度などに依存すると考えられる。

\section{4. まとめと今後の課題}

最大 $5 \mathrm{kOe}$ の磁場強度を持ち，面内で任意の角度に向きを制御 できる直交 2 軸電磁石型磁場印加 MFM を開発した. この装置で パーマロイの円盤に生じた磁気渦構造や, 長方形薄膜の還流磁区 の外部磁場に対する変化を観察し，マイクロマグネティックス計 算と合わせて議論した。、いすれも，角度制御された外部磁場に対 して理論的に妥当と考えられる磁区構造変化を観測した. 但し, 空間対称性のある磁生体でも，印加磁場の向きに対する対称性が 一部見られない磁区構造を観測した. 次世代の磁気応用デバイス

(a) $\theta=90^{\circ}$

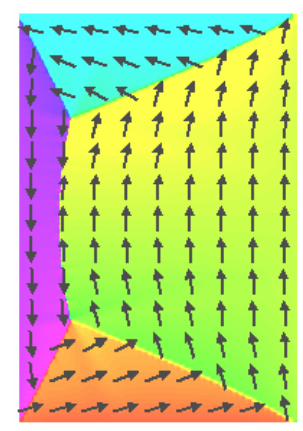

(b) $\theta=45^{\circ}$

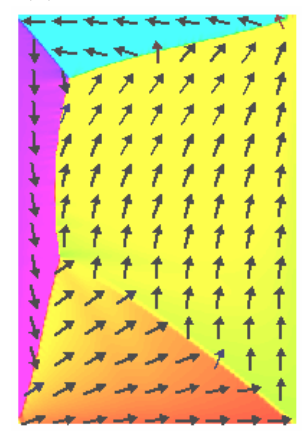

(c) $H=0(\mathrm{Oe})$

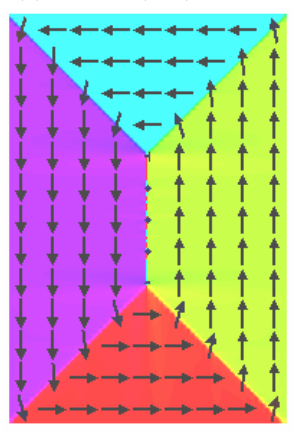

(d) $\theta=0^{\circ}$

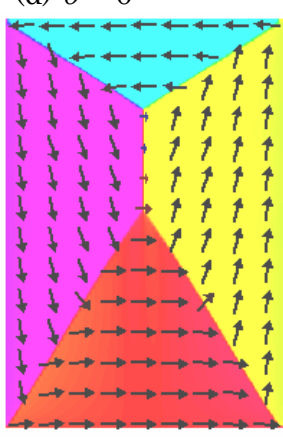

Fig. 9 Images (a)-(d) are micromagnetics simulations of MFM images (b),(c),(e) and (f) in Fig. 8.

においては, 磁壁移動や磁化反転過程の詳細な解析が必要となり, 磁場回転に対する対称性の評価は有効と考える.

水平1軸タイプの磁場印加MFMにおいては, 遠莍らによって, 探針高さを任意に設定し，探針走査はせす磁場を掃引しながら MFM 応答を検出寸る磁場スイープ MFM 法により, 磁性ドット や細線におけるナノ領域での磁化反転や磁壁運動に起因するダイ ナミックな磁化特性について報告がある。14) 今回開発した直交2 軸電磁石型磁場印加 MFM においては, 任意の磁場角度での磁場 掃引や，時間的に角度が変化する回転磁場での掃引など，更に新 しい磁場スイープ MFM の可能性がある. 今回開発した装置は試 料温度も制御可能であるため, 外部磁場と温度の両方を制御しな がら，より深く磁性体の基礎的特性を解明していく手法にしてい きたい.

本研究は数 $10 \mathrm{Oe}$ の比較的低磁場を印加した場合の測定と解析 について議論したが, 探針の保磁力（６00 Oe）を超える強磁場 を印加する場合は, MFM 探針磁化の方向の設定や, 取得した MFM 像の解釈などに特別の注意が必要であり, 磁場印加型 MFM の最大の課題であった. 最近, 伊藤らにより, 保磁力が $10 \mathrm{kOe}$ を超える高保磁力探針研究に関する報告があった. 15) このような 高保磁力探針を使えば，この課題を解決でき，より沉用的な磁区 構造解析手法として磁場印加型 MFM の重要性が増してくるもの と考えられる.

\section{References}

1) Y. Martin and H.K. Wickramasinghe: Appl. Phys. Lett. 50, 1455 (1987).

2) T. Yamaoka, K. Watanabe, Y. Shirakawabe, and K. Chinone: 
J. Magn. Soc. Jpn., 27, 429 (2003)

3) H. Kuramochi, T. Uzumaki, M. Yasutake, A. Tanaka, H. Akinaga and H. Yokoyama, Nanotechnology, 16, 24 (2005).

4) T. Yamaoka, K. Watanabe, Y. Shirakawabe, K. Chinone, E. Saitoh, M. Tanaka, and H. Miyajima: IEEE Trans. Magn., 41, 3733 (2005).

5) K. Machida, T. Yamamoto, T. Yamoka, T. Ishibashi and K. Sato: Jpn. J. Appl. Phys., 45 Part 2 [9], L265 (2006).

6) M. Tanaka, E. Saitoh, H. Miyajima, T. Yamaoka, and Y. Iye: $J$ Magn. Soc. Jpn., 29, 111 (2005).

7) T. Yamaoka, E. Saitoh, K. Machida, M. Tanaka, K. Watanabe, Y. Shirakawabe and H. Miyajima: J. Magn. Soc. Jpn., 31, 221 (2007) .

8) Y. Yasui, K. Shimomai, and M. Futamoto: J. Magn. Soc. Jpn., $31,312(2007)$
9) T. Yamaoka, Y. Ogimoto, K. Watanabe, K. Kojima, and H. Katayama: J. Magn. Soc. Jpn., 30, 472 (2006) .

10) H. Takahoshi, H. Saito, S. Ishi, T. Yamaoka and I. Okamoto: J. Magn. Soc. Jpn., 26, 284 (2002) .

11) J. Bai, H. Takahoshi, H. Ito, H. Saito, S. Ishio: J. Appl. Phys, 96, 1133(2004).

12) A. Yamaguchi, T. Ono, S. Nasu, K. Shigeto, K. Mibu, and T.Shinjo: J. Magn. Soc. Jpn., 27, 324 (2003) .

13) http://math.nist.gov/oommf/

14) Y. Endo, H. Fujimoto, S. Kumano, Y. Matsumura, I. Sasaki, Y. Kawamura, M. Yamamoto, and R. Nakatani; J. Appl. Phys, 103, 07D918-1 (2008).

15) A. Ito et al., The 31st Annual Conference on MAGNETICS in Japan, Tokyo, 14aE-10, 2007.

2008 年11月 25 日受理， 2009 年3月 4 日採録 